\title{
Erratum to: Drug shortages in Canadian anesthesia: a national survey
}

\author{
Richard Hall, MD • Gregory L. Bryson, MD • Gordon Flowerdew, ScD • \\ David Neilipovitz, MD - Agnieszka Grabowski-Comeau, RN • Alexis F. Turgeon, MD • \\ for the Canadian Perioperative Anesthesia Clinical Trials Group
}

Published online: 8 October 2013

(C) Canadian Anesthesiologists' Society 2013

\section{Erratum to: Can J Anesth/J Can Anesth (2013) 60:539-551 \\ DOI 10.1007/s12630-013-9920-z}

In the article entitled: "Drug shortages in Canadian anesthesia: a national survey" published in the June 2013 issue, Can J Anesth 2013; 60: 539-51, in Table 2, the percent value next to opioid shortage under column 2 should read "275/1,187 (23.2\%)", instead of (3.2\%). The publisher apologizes most sincerely for this error.

The online version of the original article can be found under doi:10.1007/s12630-013-9920-z.

R. Hall, MD ( $\varangle) \cdot$ A. Grabowski-Comeau, RN Division of Critical Care Medicine, Department of Anesthesiology, Dalhousie University and the Capital District Health Authority, Room 5452 Halifax Infirmary, 1796 Summer Street, Halifax, NS B3H 3A7, Canada

e-mail: rihall@dal.ca

G. Flowerdew, $\mathrm{ScD}$

Department of Community Health and Epidemiology, Dalhousie University and the Capital District Health Authority, Halifax,

NS, Canada

G. L. Bryson, MD

Department of Anesthesiology, The University of Ottawa and The Ottawa Hospital Research Institute, Ottawa, ON, Canada

D. Neilipovitz, MD

Departments of Anesthesiology and Critical Care Medicine, The Ottawa Hospital, Ottawa, ON, Canada
A. F. Turgeon, MD
Population Health and Practice-Changing Research Unit (Trauma-Emergency-Critical Care Medicine), Division of Critical Care Medicine, Department of Anesthesiology, Centre Hospitalier Universitaire de Québec (CHU) Research Center, CHU de Québec, Université Laval, Québec, QC, Canada 